\title{
First investigation on the applicability of an active noise control system on a tracked tractor without cab
}

\author{
Daniele Pochi, ${ }^{1}$ Roberto Fanigliulo, ${ }^{1}$ Lindoro Del Duca, ${ }^{2}$ Pietro Nataletti, ${ }^{3}$ \\ Gennaro Vassalini, ${ }^{1}$ Laura Fornaciari, ${ }^{1}$ Luigi Cerini, ${ }^{3}$ Filippo Sanjust, ${ }^{3}$ Diego Annesi ${ }^{3}$ \\ ${ }^{1}$ Consiglio per la ricerca e la sperimentazione in agricoltura, CRA-ING Unità di ricerca per \\ l'ingegneria agraria, Agricultural Engineering Research Unit, Monterotondo (Rome), Italy; \\ ${ }^{2}$ ACTIVE di Lindoro Del Duca, Rome, Italy; ${ }^{3}$ INAIL Ricerca, Dipartimento di Igiene del Lavoro, \\ Monte Porzio Catone (Rome), Italy
}

\begin{abstract}
In last years, several research teams pointed their attention on the application of active noise control systems (ANC) inside the cabs of agricultural tractor, with the purpose of reducing the driver exposition to noise, that is only partially controlled by the frame of the cab. This paper reports the results of a first experience that aimed at verifying the applicability of an ANC on a medium-high power, tracked tractor without cab. The tested tractor was a Fiat Allis $150 \mathrm{~A}$, equipped with rear power take off, used in the execution of deep primary tillage in compact soils. It is a tracked tractor without cab, with maximum power of $108.8 \mathrm{~kW}$ at 1840 $\mathrm{min}^{-1}$ of the engine. The ANC consists of a control unit box based on a digital signal processor (DPS), two microphones, two speakers and a power amplifier. The instrumentation used in noise data collecting and processing consisted of a multichannel signal analyzer (Sinus Soundbook), a 1/2" microphone capsule and an acoustic calibrator, both Bruel \& Kjaer. The study aimed at evaluating the behaviour of the ANC by means of tests carried out under repeatable conditions, characterized by pre-defined engine speed values. Three replications have been made for each engine speed. The sampling time was $30 \mathrm{~s}$. Two series of tests were performed in order to compare the results observed with the ANC on and off. The engine speed adopted in the study ranged from $600 \mathrm{~min}^{-}$ ${ }^{1}$, up to $2000 \mathrm{~min}^{-1}$ (maximum speed) with steps of $100 \mathrm{~min}^{-1}$. The ANC proved to be effective in the interval of speed between 1400 and 1700 $\mathrm{min}^{-1}$, where the samplings have been intensified, adopting steps of 50
\end{abstract}

Correspondence: Daniele Pochi, Unità di ricerca per l'ingegneria agraria, Via della Pascolare, 16, 00015 Monterotondo (Rome), Italy.

Tel. +39.06.90675232 - Fax: +39.06 .90625591 .

E-mail: daniele.pochi@entecra.it

Keywords: sound pressure level, attenuation, tractor.

Contributions: the authors contributed equally.

Conflict of interests: the authors declare no potential conflict of interests.

(C) Copyright D. Pochi et al., 2013

Licensee PAGEPress, Italy

Journal of Agricultural Engineering 2013; XLIV(s2):e152

doi:10.4081/jae.2013.s2.e152

This article is distributed under the terms of the Creative Commons Attribution Noncommercial License (by-nc 3.0) which permits any noncommercial use, distribution, and reproduction in any medium, provided the original author(s) and source are credited. $\min ^{-1}$. In such an interval, the attenuation observed with the ANC system on appeared evident both as weighed A sound pressure level (from 1.29 up to $2.46 \mathrm{~dB}(\mathrm{~A})$ ) and linear (from 4.54 up to $8.53 \mathrm{~dB}$ ). The best performance has been observed at the engine speed of $1550 \mathrm{~min}^{-1}$, with attenuations, respectively of $2.46 \mathrm{~dB}(\mathrm{~A})$ and $7.67 \mathrm{~dB}$. Outside of the engine speed interval $1400-1700 \mathrm{~min}^{-1}$, the attenuations always resulted lower than $1 \mathrm{~dB}(\mathrm{~A})$ for the weighed $\mathrm{A}$ sound pressure level and between 0.66 and $7.72 \mathrm{~dB}$.

\section{Introduction}

At about twenty-five years since the beginning of systematic work on the active noise control, we can draw some important conclusions and suggest programs and reasonable results for the foreseeable future (Hasegawa et al., 1992; Kuo and Vijayan, 1994). The enthusiasm of the researchers, emerging from the reading of the considerable amount of works reported in the Proceedings of the Conference 'ACTIVE-95', the first conference dedicated exclusively to this area of research, gradually decreased over time. The few applications that were successful in industry were primarily the result of large investments in applied research of the products and were aimed at very large market segments (Elliot, 2000). For instance, it was the case of the active headphone and of the active-cancelling microphone. The problem of noise reduction in the cab of tractors, as well as other vehicles, it is very sensitive today both for the preservation of health and for a greater operator comfort. For several years, research groups turned their attention to the active noise control into cabs of tractors and industrial vehicles trying to reduce operator exposure to the noise, that is only partly controlled by the cab structure (Del Duca and Nataletti, 2009; Nataletti and Del Duca, 2010).

This work describes a first experience aimed at verifying and evaluating the application of a system for active noise control on an agricultural tracked tractor of medium-high power, without cab. This type of vehicles is largely diffused and has significant noise impact on the operators. The originality of this study lies precisely in the application of an active control system in absence of cab. The system used, ATH311, already successfully used in tractors with cab, consists of a control unit based on the digital signal processor DSP. A widespread feedback algorithm configuration was used in the experiment. It will be briefly described in the following. In experimental tests it was implemented in a configuration with two feedback channels (Figure 1).

\section{Materials and methods}

The active noise control, henceforth indicated with the term ANC (Active Noise Control), is a technique characterized by the fact that 
the reduction of noise (primary noise) is obtained electronically generating a noise (secondary noise) that creates a destructive interference with the first, unlike the conventional techniques (passive) in which the reduction of noise is obtained with the use of sound absorbing and soundproofing materials and structures.

The tractor tested was a Fiat Allis $150 \mathrm{~A}$, commonly employed in heavy works (plowing, subsoiling, etc.) in tenacious soil and fitted with a rear power take off. It is a tracked tractor, without cab, with maximum power of $108.8 \mathrm{~kW}$ at engine speed of $1840 \mathrm{~min}^{-1}$. The diesel engine is turbocharged, with displacement of $8102 \mathrm{~cm}^{3}$. Its total mass is approximately $12150 \mathrm{~kg}$. It has steel tracks the tension of which is hydraulically adjustable. The gear box has three-speed gear ratios and a two gear range reducer (slow and fast). The maximum velocity is $2.41 \mathrm{~m} \mathrm{~s}^{-1}$ in III fast.

The system for the active control of the noise consisted of (Figure 2):

1. control unit based on the digital signal processor DSP;

2. stereo power amplifier Class D $(600 \mathrm{~W})$;

3. couple of electret microphones with cables and jacks,

4. woofer speaker pair of 13 ".

In the configuration, the standard algorithm was implemented with an original routine software aimed at increasing the efficiency, stabil-

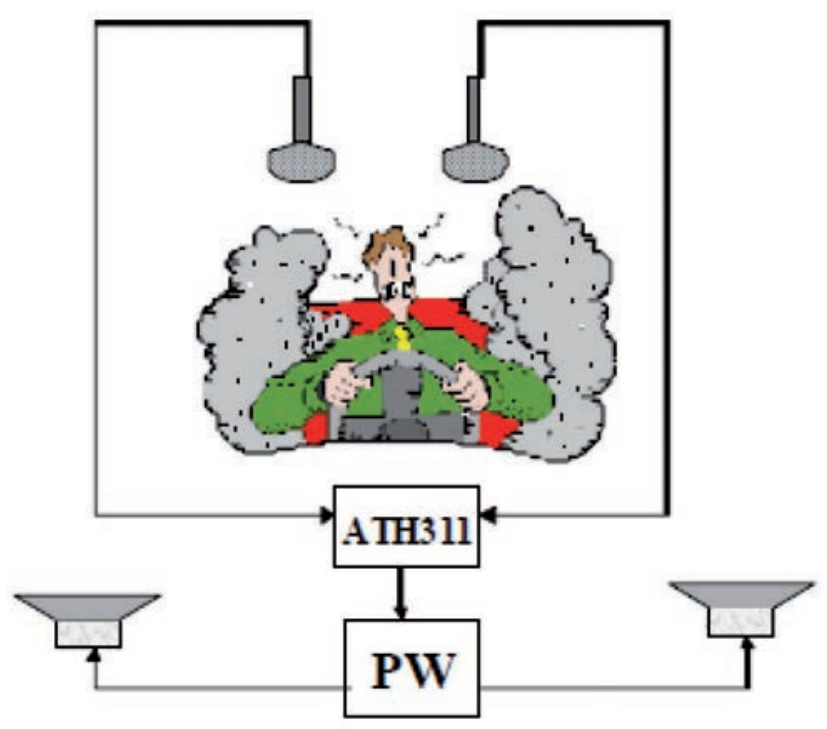

Figure 1. Configuration of the two channel feedback system. ity and reliability of the system.

The sound measurements were recorded with the following instrumental chain:

- Sound Book - eight channels datalogger / signal processor with special software "Samurai";

- $\quad$ microphone capsule 1/2" Brüel \& Kjær, mod. 4189, with windscreen; - $\quad$ microphone calibrator Brüel \& Kjær, mod. 4231;

The tractor was fitted with a magnetic tachometer for measuring engine speed. The tests aimed at evaluating the system of active noise control.

For this purpose, the measurements were carried out in repeatable conditions at various rotation speeds of the engine, first with the active control system turned on, then off. For each speed, 3 replications were performed with a sampling time of $30 \mathrm{~s}$. The measurements were made with engine speed increments of $100 \mathrm{~min}^{-1}$ in the range $600-2000 \mathrm{~min}^{-}$ 1. In a second time, in the interval between 1400 and $1700 \mathrm{~min}^{-1}$, in which the system resulted more efficient, the sampling occurred with increments of $50 \mathrm{~min}^{-1}$.

\section{Results}

Figure 3 shows the frequency analysis in $1 / 3$ of octave relating to the noise measured in the operator's station, with rotation speed of the engine of $600 \mathrm{~min}^{-1}$ (a), $1550 \mathrm{~min}^{-1}$ (b), and $2000 \mathrm{~min}^{-1}$ (c). The curves refer both to the ANC system "off " (brown and red lines ) and "on" (blue and green).

In general, it can be noticed that the weighting filter A has the maximum effect on the frequencies ranging from 20 to $800-1000 \mathrm{~Hz}$. Furthermore, it is evident that the frequency range in which the ANC system is more effective is between 40 and $200 \mathrm{~Hz}$.

An attentive observation of the analysis in frequency shows that, in the cases in which the lower components of the spectrum (relative to the engine) prevail, the ANC system provides the best performance 40 $\mathrm{Hz}$ (Figure $3 \mathrm{a}$ and $\mathrm{b}$ ).

Moreover, when the same low components of the spectrum are very pronounced in comparison to the other harmonic components, as in Figure $3 \mathrm{~b}$, the best results are observed on the single frequencies which the system operates and on the total value in $\mathrm{dB}(\mathrm{A})$ as well.

Otherwise, from $1800 \mathrm{~min}^{-1}$ up to the max rotation speed (Figure 3 c), the lines of the spectrum are almost all at the same level, and the effect of attenuation results less effective.

The test results are reported in Table $\mathrm{n} .1$ and the above considerations indicate the opportunity to separate evaluation of the values obtained in linear and the A-weighted values. In the first case, the operation of the ANC system provides good attenuation, ranging from a
A)

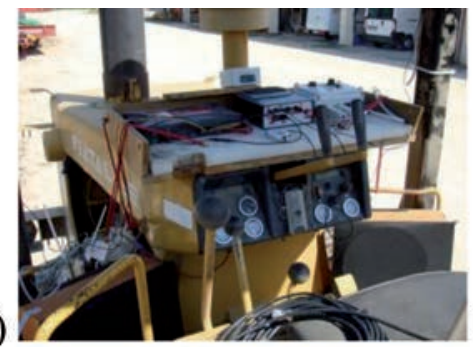

B)

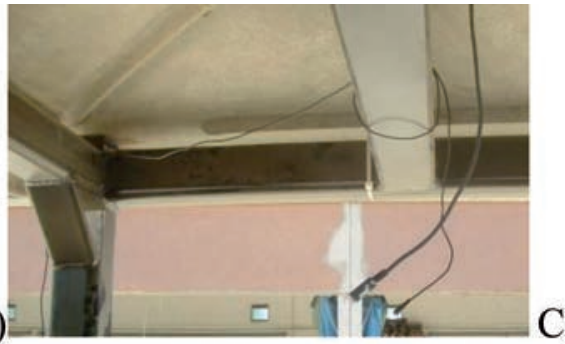

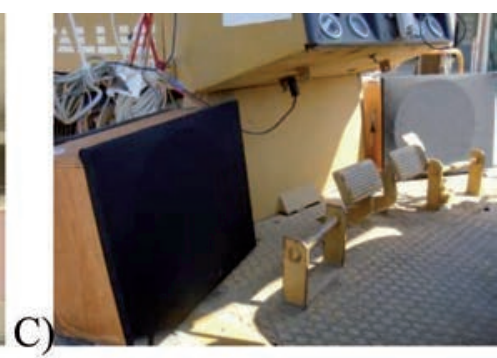

Figure 2. System for the active control of noise composed by a control unit based on the digital signal processor DSP and a power amplifier (A), two microphones (B), two speakers (C). 
minimum of $3.0 \mathrm{~dB}$ to a maximum of $8.5 \mathrm{~dB}$ at engine speeds lower than $1700 \mathrm{~min}^{-1}$.

As already mentioned above, for the rotation speeds higher than $1800 \mathrm{~min}^{-1}$, the system is less effective, with attenuations ranging from 0.7 to $1.4 \mathrm{~dB}$.

As to the A weighting filter, its action, inside the interval of the spectrum between 20 and $1000 \mathrm{~Hz}$, almost completely cancels the ANC system action for engine speeds comprised between 600 and $1300 \mathrm{~min}^{-1}$, where the maximum attenuation observed was $0.9 \mathrm{~dB}(\mathrm{~A})$.

The attenuation level increased in the interval $1350-1800 \mathrm{~min}^{-1}$, with values ranging from 0.9 up to $2.5 \mathrm{~dB}(\mathrm{~A})$.

Even less significant differences were observed at higher engine speeds, with a light tendency to an increase of the global noise level at 1800 and at $1900 \mathrm{~min}^{-1}$, while at $2000 \mathrm{~min}^{-1}$ the attenuation resulted of only $0.1 \mathrm{~dB}(\mathrm{~A})$.

Considering the higher action value $85 \mathrm{~dB}$ (A) and the limit value of $87 \mathrm{~dB}(\mathrm{~A})$ defined in the Italian Legislative Decree no. 81/2008, for the first, the use of the system for the first ANC, at speeds of 1400 and 1450 $\mathrm{min}^{-1}$, leads to a standardized level of exposure of the operator, for a working day of $8 \mathrm{~h}$, which is within the range of lower risk.

As to the limit value, at the engine speeds of 1500 and $1550 \mathrm{~min}^{-1}$, the ANC system seems capable to reduce the level below it (Table 1).

\section{Conclusions}

The study described in the present paper aimed at contributing to the improvement of the health safe and comfort levels through the reduction of the noise level to which the drivers of tractors without cab are exposed. The tests, carried out on a tracked tractor, using an active noise control system based with an original feedback configuration, provided good results. The most significant attenuations (up to $8.5 \mathrm{~dB}$ ) occurred in the interval of engine speed between 1000 and $1400 \mathrm{~min}^{-1}$, where the action of the ANC system appeared particularly effective towards the prevailing low frequencies. However, even at higher speeds, where the attenuation of the low frequencies is less significant in the prevention of the hearing damage, the ANC system could contribute to an increase of the level of comfort, through reduction of loss of attention and hearing fatigue. However, the link between the exposure to low frequency noise and the loss of attention and working efficiency should be suitably studied.
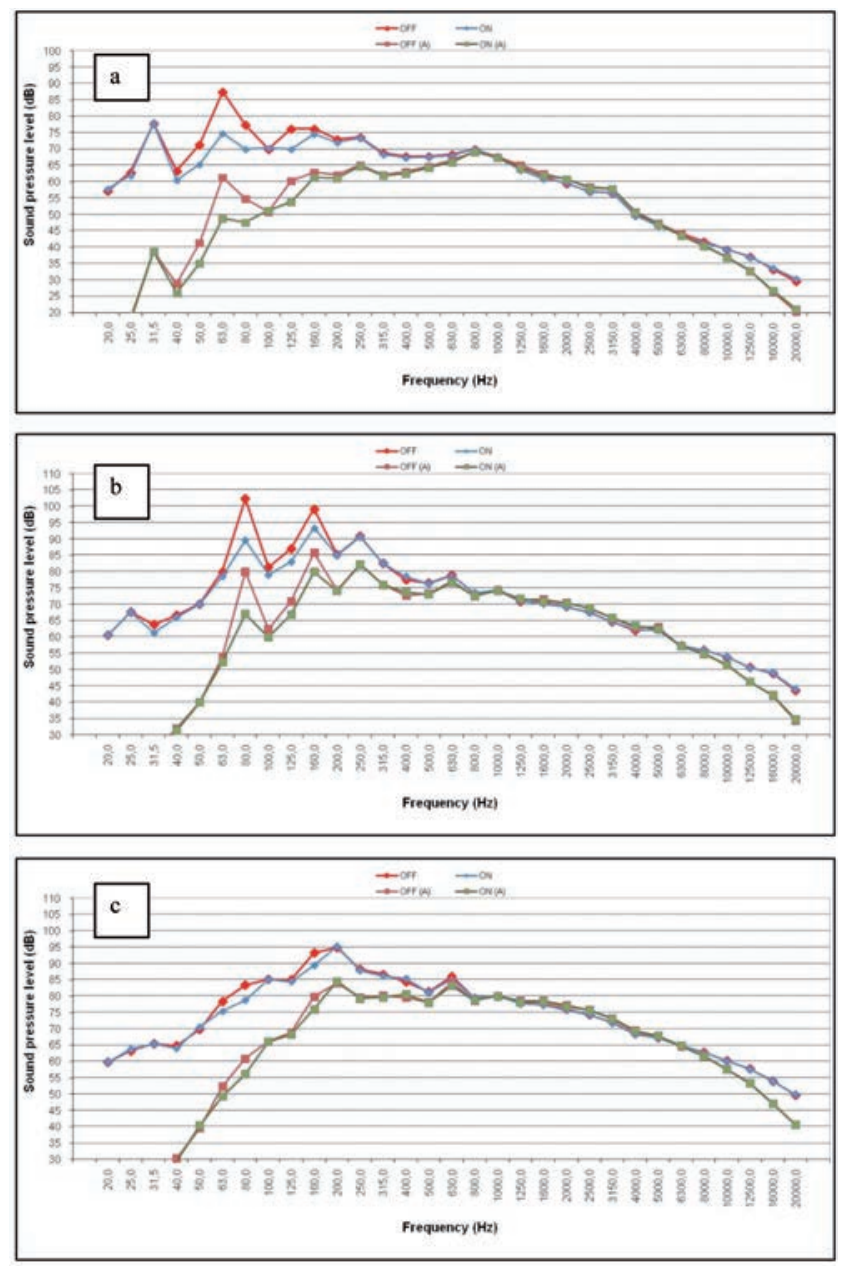

Figure 3. Spectrum in $1 / 3$ of octave relating to the tests with the ANC system, "off" and "on" at the engine speeds of $600 \mathrm{~min}^{-1}(\mathrm{a}), 1550 \mathrm{~min}^{-1}(\mathrm{~b})$, $2000 \min ^{-1}$ (c).
Table 1. Results obtained in the noise measurements with the ANC system connected (on) and disconnected (off) at different engine speeds.

\begin{tabular}{|c|c|c|c|c|c|c|c|c|c|c|c|c|c|}
\hline \multirow{2}{*}{ 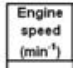 } & \multirow[b]{2}{*}{\begin{tabular}{|l} 
Active \\
control
\end{tabular}} & \multicolumn{3}{|c|}{$\frac{L_{\text {hey }} d B(A)}{R}$} & \multirow[b]{2}{*}{ rago } & \multirow{2}{*}{\begin{tabular}{|c|} 
Stand \\
Dov.
\end{tabular}} & \multirow[b]{2}{*}{$\Delta$} & \multicolumn{3}{|c|}{$\frac{L_{49} d B}{\text { Retertions }}$} & \multirow[b]{2}{*}{ Verage } & \multirow{2}{*}{$\begin{array}{c}\text { Stand } \\
\text { ondev. }\end{array}$} & \multirow[b]{2}{*}{1} \\
\hline & & & & 3 & & & & & & & & & \\
\hline & off & n5: & 754 & 756 & 758 & 045 & & 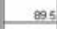 & $\infty 3$ & 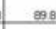 & . & 0.26 & \\
\hline & on & 75: & 748 & 752 & 75.2 & 0.6 & 0.5 & 899 & 81 & $\infty$ & w. & 1.17 & 5 \\
\hline \multirow[t]{2}{*}{700} & off & res & 700 & $\pi 9$ & 70.1 & $0 x$ & & 34 & ss: & $\$ 0$. & \$.1. & 061 & \\
\hline & No & $m$ & $n_{0}$ & $\pi$ & $n, 3$ & 0.5 & .9 & 875 & $\theta 7$ & $\infty$ & wa & 0.2 & \\
\hline \multirow[t]{2}{*}{$\infty 0$} & off & $\pi 01$ & 786 & 782 & $n .4$ & 1) $0 x$ & & 993 & 930 & 9 & $n$ & $a x$ & \\
\hline & on & ra & $\pi 4$ & $m$ & $n s$ & $0 x$ & 0.8 & $\infty$ & कo & क & s. & 0.6 & 1 \\
\hline \multirow[t]{2}{*}{900} & off & 79 & 798 & $\infty 2$ & 79. & 019 & & ri & 92 & $\infty$ & r. & 0,4 & \\
\hline & on & $\pi 9$ & 795 & 800 & 79.6 & 033 & 0.3 & 879 & $\infty$ & \% & $\ldots$ & $0 *$ & 3 \\
\hline \multirow[t]{2}{*}{1000} & off & a1. & 810 & $\infty 0$ & 810 & - 0.19 & & 914 & 919 & 91. & $M x$ & 033 & \\
\hline & on & $\infty$ & \begin{tabular}{|l|} 
\\
\end{tabular} & $\infty 02$ & n.7.7 & I onf & 0.3 & $\infty$ & $\infty$ & $\infty$ & s.s & 058 & \\
\hline \multirow[t]{2}{*}{100} & loff & 018 & 812 & $\infty 0$ & 81.2 & 2027 & & 947 & 93 & 905 & $n x$ & 0,4 & \\
\hline & ON & 81 & $\infty 9$ & 000 & s.0. & 0.4 & ...5 & 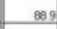 & $\$ 7$ & $\infty$ & $\infty 2$ & ar. & + \\
\hline \multirow[t]{2}{*}{1200} & off & 839 & 895 & 801 & s.s. & 0.00 & & $\infty$ & 96 & $\infty$ & $\$ .1$ & 0.5 & \\
\hline & on & 8 & 824 & 027 & 32.7 & $0 x$ & 0 & $\infty$ & $\infty$ & 9 & r. & 0.9 & 5 \\
\hline \multirow[t]{2}{*}{1300} & off & Bat & 836 & 835 & 8.6 & 0.15 & & st & 96 & $\approx$ & $5 .$. & 0.34 & \\
\hline & on & 83 & $\infty$ & 804 & $s .4$ & 400 & 0.2 & 919 & 922 & re & ris & 027 & 4 \\
\hline \multirow[t]{2}{*}{1300} & off & 84 & 845 & 807 & \$.2. & 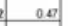 & & 96 & 93 & $9 x$ & $n s$ & 12 & \\
\hline & on & 84 & 800 & 0. & $n x$ & 033 & ..4. & 922 & 2,3 & 9 & n.x. & 005 & 5 \\
\hline \multirow[t]{2}{*}{1350} & off & 84 & 845 & 69 & 2.5.5 & 0.51 & & $m$ & $n_{3}$ & s & $n .$. & 0.6 & \\
\hline & on & 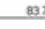 & 897 & 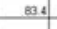 & 8.6 & $5 \quad 016$ & -9.9 & \begin{tabular}{|l}
928 \\
\end{tabular} & 928 & 9 & 92.5 & 0.58 & 6. \\
\hline \multirow[t]{2}{*}{1000} & off & 85 & कos 3 & $\infty$ & 853 & $0 x$ & & 1015 & $m$ & 1000 & me. & 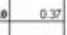 & \\
\hline & on & 23 & 00 & 805 & 8.6 & 0,10 & 13 & 935 & 90 & 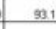 & $n s$ & $0 . x$ &. \\
\hline 1450 & off & 87. & 100 & 2066 & $26 x$ & - $0 x$ & & 10032 & 1024 & 1023 & ma.x & 0.8 & \\
\hline & ON & 84 & 89 & 8 & sus & 010 & 20 & 245 & कs: & 2 & $x_{x}$ & 0.0 & 7 \\
\hline 1500 & off & $\infty$ & 89 & 200 & 880 & 013 & & 1036 & 1908 & 1093 & 103.2 & 0.2 & \\
\hline & ON & 05 & कs & exs & 85s. & 0,19 & 24 & 200 & 94 & St: & s.e & 0.55 & 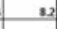 \\
\hline 1580 & off & 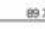 & \begin{tabular}{|l|l|} 
\\
\end{tabular} & Q & 0.5 & 024 & & 1046 & 1043 & $104:$ & mat. & $4 \quad 019$ & \\
\hline & ON & 872 & 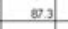 & $\infty$ & $m 0$ & 05: & 25 & 97 & 97 & क & 8.7 & 122 & 7 \\
\hline 1000 & off & $\infty$ & $\infty 21$ & 20.1 & 20.1 & 000 & & 1042 & 1044 & 104 & 2004 & 0.15 & \\
\hline & an & 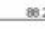 & $\$ 1$ & 803 & 8.5 & 028 & 22 & 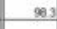 & 2 & 63 & $\pi x$ & 138 & 4 \\
\hline 1650 & off & $\infty ?$ & $\infty$ & 28 & $\infty$ & 0.21 & & 1098 & 1003 & 1006 & $m . x$ & 0.12 & \\
\hline & on & 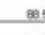 & (x) & 男 & 883 & 019 & 1. & $\$ 5$ & 98 & 80 & s. & 018 & \\
\hline 1000 & off & 899 & $\$ 1$ & 28 & 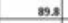 & 0.13 & & 103 & 1098 & 103 & $m .1$. & 0.13 & \\
\hline & ON & 2 & 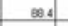 & $m$ & . s.s.s & $5 \quad 0.4$ & 1.3 & 978 & 205 & क & $9 x$ & 6. $\quad 0 \pi 8$ & \\
\hline 1000 & off & 08 & 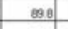 & 200 & 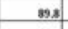 & - 0 ou & & 1009 & 101 & 1010 & 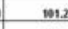 & $\begin{array}{l}2 \quad 039 \\
\end{array}$ & \\
\hline & 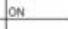 & 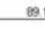 & & -80 & 90.2 & 100 & . 4. & net & 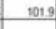 & 0. & $n x$ & *. 223 & 1 \\
\hline 1900 & off & & & & 30 & 000 & & & & 10 & 100.4 & 105 & \\
\hline & & & & & $n$ & 108 & 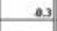 & & & 10 & $n$ & 20 & \\
\hline $2 x$ & & 91 & 91 & & n & 009 & & & & $\infty$ & s.t. & 011 & \\
\hline & & 91: & . 195[ & & M.A. & 016 & & $8 \times 6$ & 969 & & 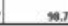 & 7] 0111 & \\
\hline
\end{tabular}


The results of these first experiences indicate that further tests are needed with the purpose of observing the behaviour of the ANC system during the execution of the classic operations the tractor is devoted to, such as ploughing or harrowing, and evaluating its capability of reaction to the variation of the conditions of working and, consequently, of noise.

Possible improvements of the system could be achieved through the use of audio components with more suitable characteristics, with reference to the working target represented by limited intervals of frequency (for instance between 40 and $200 \mathrm{~Hz}$, as evidenced in the tests).

\section{References}

Del Duca L., Nataletti P. 2009. Il controllo attivo del rumore: stato dell'arte e prospettive future. Rivista Italiana di Acustica 33 (4): 9-23.

Nataletti P., Del Duca L. 2010. Active control of noise in the cabins of tractor and earth moving machinery. In Proc. 8th Int. Conf. IOHA, Rome, Italy.

Elliott S.J. 2000. Signal Processing for Active Control, Academic Press. Hasegawa S., Tabata T., Kinoshita A., Hyoto H. 1992. The development of an active noise control system for automobiles. Soc. Of Automotive Engineers Technical Paper, N. 922086.

Kuo S.M., Vijayan D. 1994. Adaptive algorithms and experimental verification of feedback active noise control systems. Noise Control Eng. J., 42 (2): 37-46. 